\title{
A inclusão de catadores em programas de coleta seletiva: da agenda local à nacional
}

\author{
The inclusion of collectors in selective recyclable waste programs: from the local to the \\ national agenda
}

\author{
Maria Cecília Gomes Pereira ${ }^{1}$ \\ Marco Antonio Carvalho Teixeira ${ }^{2}$
}

\section{Resumo}

O presente trabalho tem como objetivo discutir como a inclusão social e produtiva de catadores de materiais recicláveis, antes presente apenas na agenda de políticas públicas locais, alcançou a agenda governamental nacional. Recorre-se à discussão teórica de múltiplos fluxos, de Kingdon (1995), apontando suas limitações para a análise do fenômeno investigado. Os procedimentos metodológicos adotados foram: revisão bibliográfica, observação participante em eventos, levantamento de dados secundários, conversas espontâneas e entrevistas semiestruturadas. Observa-se que, em certa medida, houve a junção dos três fluxos abordados por Kingdon (1995), a saber, um problema que ganhou reconhecimento público, um ambiente político favorável à entrada de questões sociais na agenda e uma alternativa que se apresentou viável para a solução do problema - a inclusão de catadores em programas de coleta seletiva -, mas que não responde completamente as dimensões do problema. Nesse processo, organizações da sociedade civil tiveram um papel fundamental. No entanto, o modelo de múltiplos fluxos não apenas desconsidera um processo de formação de agenda de "baixo para cima", como também deixa de lado a discussão sobre a influência que atores extrainstitucionais, como organizações da sociedade civil, possam exercer nesse processo. Desse modo, o modelo não dá conta de explicar as complexas relações entre Estado e sociedade civil na realidade brasileira.

Palavras-chave: Catadores de materiais recicláveis. Formação de agenda. Políticas públicas.

\begin{abstract}
This article aims to discuss the issue of social and productive inclusion of collectors of recyclable materials, present previously only in local public policy agendas and that has now reached the national governmental agenda. The theoretical discussion is based on Kingdon's (1995) multiple streams theory, highlighting its limitations in the analysis of the phenomenon under study. The methodological procedures used were: bibliographical review, participative

Artigo submetido em 23 de março de 2011 e aceito para publicação em 04 de agosto de 2011.

1

Mestre em Administração Pública e Governo pela Escola de Administração de Empresas de São Paulo da Fundação Getulio Vargas (EAESP-FGV), onde também é pesquisadora do Centro de Estudos em Administração Pública e Governo (CEAPG). Endereço: Av. Nove de Julho 2.029, $11^{\circ}$ andar, Bela Vista, CEP 01313-902, São Paulo - SP, Brasil. E-mail: cecilia.pereira@fgv.br

2

Doutor em Ciências Sociais pela PUC-SP; Professor do Departamento de Gestão Pública e do Programa de Pós-Graduação em Administração Pública e Governo da (EAESP-FGV), onde também é pesquisador do Centro de Estudos em Administração Pública e Governo (CEAPG). Endereço: Av. Nove de Julho 2.029, 11ํandar, Bela Vista, CEP 01313-902, São Paulo - SP, Brasil. E-mail: marco.teixeira@fgv.br
\end{abstract}


observation in events for collectors secondary data collection, spontaneous conversations and semi-structured interviews. We observed that to a certain extent there was a junction of Kingdon's (1995) three streams: a problem gained public recognition, a political environment favorable to the emergence of issues such as this agenda, and a viable alternative to the problem presented itself - the inclusion of collectors in solid waste selective collection programs -, which do not respond completely to the dimensions of the problem. Civil society organizations played an essential role in this process. However, the multiple streams model does not conceive of a "bottom-up" agenda setting process, nor does it consider the influence of extra-institutional actors, such as civil society organizations, on the agenda setting process. As such, the model is unable to explain the complex relations between the State and civil society in Brazilian reality.

Keywords: Collectors of recyclable materials. Agenda setting. Public policies.

\section{Introdução}

A sobrevivência por meio da cata de materiais no lixo desnuda uma das faces da elevada desigualdade social existente no Brasil. Aqueles que sobrevivem do lixo - os catadores de materiais recicláveis - estão presentes nas ruas, em aterros ou em lixões ${ }^{3}$ da maioria das cidades brasileiras, trabalhando em condições adversas e precárias. Atuam como "operários terceirizados" da indústria da reciclagem, desprovidos de qualquer direito trabalhista, bem como dos demais direitos que configuram o exercício da cidadania (LAYARGUES, 2002; BOSI, 2008).

Por sua vez, a atividade dos catadores está inserida em um dos principais problemas ambientais urbanos: a disposição final do lixo - que aumenta cada vez mais, em uma lógica de produção marcada pelo consumismo (BAUMAN, 2005), na qual a reciclagem, muitas vezes, é vista como uma "solução" (LAYARGUES, 2002). Sem desmerecer os méritos e a importância da reciclagem realizada no país, é necessário apontar algumas dinâmicas contraditórias existentes, sobretudo na forma de inserção de catadores nesse processo. Os catadores estão na base da cadeia produtiva da reciclagem, trabalhando em condições desumanas e sem acesso a quaisquer direitos. Uma vez que estão inseridos precariamente, os grandes lucros desse processo ficam com as indústrias recicladoras, as quais muitas vezes valem-se do discurso social e ambiental, sem fazer menção ao fato de que a reciclagem esconde três problemas centrais: a necessidade de redução do consumo; de rever os padrões de produção, como as estratégias produtivas de descarte e da obsolescência planejada; e a exploração do trabalho de indivíduos marginalizados pela sociedade (LAYARGUES, 2002; LEAL, GONÇALVEZ e THOMAZ JUNIOR, 2009).

Soma-se a essa dinâmica, o fato de que os catadores foram e, muitas vezes, ainda são "vistos" pela sociedade como "delinquentes" e/ou "mendigos" que "sujam" os centros urbanos. Tal percepção gerou, e ainda gera, "políticas higienistas" por parte do poder público de grande parte das cidades brasileiras. Entretanto, o poder público tem um papel fundamental na promoção de políticas públicas de inclusão efetiva desses trabalhadores. O reconhecimento do problema e sua inserção efetiva na agenda de políticas públicas dos governos locais é um processo que ainda está em construção, com dinâmicas diversificadas e específicas em cada município. Nesse processo, diversos atores estão envolvidos, como indústrias, consumidores, organizações da sociedade civil, governos, burocracia estatal e os catadores. Estes últimos têm se organizado em cooperativas e associações desde o final da década de 1980.

As primeiras experiências associativas de catadores no Brasil iniciaram-se em São Paulo, Porto Alegre e Belo Horizonte. Em São Paulo, por meio do trabalho de apoio à população de rua, desenvolvido pela Organização de Auxilio Fraterno (OAF), foi criada a Associação dos Catadores de Papel, em 1986. Mais tarde, em 1989, esta se tornou a Cooperativa dos Catadores de Papel, Papelão, Aparas e Materiais Reaproveitáveis (Coopamare). Neste mesmo ano, durante a gestão Luiza Erundina (1989-1992) foi

${ }^{3}$ Vazadouro de resíduos sólidos a céu aberto. 
implantado o primeiro programa de coleta seletiva da cidade, no entanto, nas gestões seguintes sofreu várias descontinuidades e retrocessos (JACOBI e VIVEIROS, 2006). Em Porto Alegre, no ano de 1986, foi criada a Associação dos Catadores de Material de Porto Alegre, na Ilha Grande dos Marinheiros, com o apoio do trabalho eclesial de base da Igreja Católica. Em 1990 foi implantada a coleta seletiva no município durante a gestão petista de Olívio Dutra (1989-1992) (MARTINS, 2004). Em Belo Horizonte, depois do trabalho de apoio aos catadores realizado pela Pastoral de Rua, em 1990, foi constituída a Associação dos Catadores de Papel, Papelão e Material Reaproveitável (Asmare). Em 1993, foi construído o programa de coleta seletiva de Belo Horizonte em um trabalho conjunto com a Asmare durante a gestão de Patrus Ananias (1993-1996) (PEREIRA, 2011). É interessante observar que as três experiências têm sua origem em trabalhos desenvolvidos por organizações da Igreja Católica, e que nas três cidades os programas de coleta seletiva foram criados durante gestões do Partido dos Trabalhadores (PT).

Ao longo das décadas seguintes, várias associações e cooperativas de catadores foram formadas pelo Brasil, e também alguns governos locais implantaram programas de coleta seletiva ${ }^{4}$ com inclusão de catadores. A partir do final da década de 1990 e nos anos 2000, os catadores foram se articulando com apoio de uma rede de organizações da sociedade civil e formaram o Movimento Nacional dos Catadores de Materiais Recicláveis (MNCR), em 2001. Gradativamente o tema da inclusão social e produtiva de catadores foi ganhando repercussão pública e espaço na agenda de governos locais, tendo, em 2003, no governo Lula, alcançado a agenda governamental nacional. É importante destacar que tais processos não foram simples, tampouco lineares, mas sim marcados por dinâmicas variadas e conflitos sociais.

No âmbito do governo federal, em 2003, por decreto presidencial, foi criado o Comitê Interministerial de Inclusão Social de Catadores de Materiais Recicláveis. Também foi publicado o decreto 5.940, de 2006, que prevê que todas as repartições públicas da administração direta ou indireta devam fazer coleta seletiva e doar os materiais para cooperativas de catadores. Por meio da Lei 11.445/07, que altera a Política Nacional de Saneamento, permitiu-se que as administrações públicas pudessem contratar com dispensa de licitação, as organizações de catadores de materiais recicláveis para a prestação de serviços de coleta seletiva. Por sua vez, dentro do Ministério do Desenvolvimento Social (MDS), teve início a realização de ações de apoio aos catadores, ligadas à inclusão social e produtiva. Outro avanço em âmbito federal foi a aprovação, em 2010, da Política Nacional de Resíduos Sólidos (Lei $n^{\circ}$ 12.305), que prevê a inserção de catadores em programas de coleta seletiva municipais como requisito do Plano de Gestão Integrada de Resíduos Sólidos, a ser elaborado por todos os municípios.

A inserção do tema na agenda governamental nacional, a partir de 2003, foi um avanço importante para o seu enfretamento, uma vez que o governo federal tem grande potencial de indução e coordenação de políticas públicas, o que se faz necessário quando se considera o modelo de federalismo brasileiro, as desigualdades inter e intrarregionais (SOUZA, 2002) e principalmente os desafios em que se inserem os catadores. Embora a gestão dos resíduos sólidos seja atribuição dos municípios, a União tem um papel fundamental nesse processo.

Convém destacar que o foco deste trabalho não está em uma política pública de feição puramente estatal ou mesmo de uma ação nos moldes da chamada responsabilidade social empresarial. A trajetória da experiência em questão tem origem em diferentes espaços de interação, nos quais sociedade civil, Estado e setores privados foram mobilizados, em diferentes momentos, numa perspectiva construtiva, para a viabilização de uma ação coletiva de inclusão social, em consonância com os princípios da Gestão Social.

${ }^{4}$ Conforme dados da Pesquisa Nacional de Saneamento Básico (PNSB) realizada em 2008, 994 municípios brasileiros declararam ter programas de coleta seletiva, com maior concentração nas regiões Sul e Sudeste (IBGE, 2010). Embora ainda seja um número pequeno, houve um avanço em comparação aos levantamentos anteriores da PNSB. Em 1989 foram identificados 58 programas de coleta seletiva no país; em 2000 esse número cresceu para 451, chegando a 994 em 2008 (IBGE, 2010). Sem dúvida houve um avanço, no entanto, ainda faltam estudos que avaliem a efetividade desses programas nos diferentes municípios brasileiros. 
Como afirmam Schommer e França Filho (2008, p. 66) "o termo Gestão Social sugere assim que, para além do Estado, a gestão das demandas e necessidades do social pode se dar pela própria sociedade, por meio de suas mais diversas formas e mecanismos de auto-organização" que geram pressão social, negociação política e demandas aos governos e esses podem atendê-las sob a forma de políticas públicas. Tratando também desse assunto, Tenório $(2008$, p. 40) chama atenção para a inversão da lógica capitalista presente nas ações permeadas pela gestão social. Para ele, existe um grande potencial para a inversão da ordem de categorias importantes como de capital-trabalho para trabalho-capital e de Estado-Sociedade para Sociedade-Estado, evidenciado que, nesse processo, a pessoa, ou o grupo social, podem estar acima da racionalidade meramente econômica. A inserção, no caso de catadores, pode ocorrer pelo protagonismo do grupo em uma luta para não se tornarem meramente úteis aos mecanismos de reprodução capitalista, mas sim para exercerem seus direitos como cidadãos.

Considerando o breve contexto exposto acima, o presente trabalho tem como objetivo discutir como o tema da inclusão social e produtiva de catadores de materiais recicláveis, antes presente apenas na agenda de políticas públicas locais, alcançou a agenda governamental nacional. Neste trabalho, se buscará compreender uma dinâmica de formação de agenda de "baixo para cima", ou seja, que parte inicialmente de realidades locais e alcança a agenda governamental federal. O trabalho se insere em uma discussão repleta de desafios, uma vez que há poucos estudos no Brasil que se debrucem sobre o processo de formação de agenda de políticas públicas (VIANA, 1996; CAPELLA, 2006; SOUZA, 2006; CALMON e COSTA, 2007).

Os procedimentos metodológicos adotados foram: revisão bibliográfica; observação participante em eventos ligados ao tema, principalmente do MNCR; levantamento de dados secundários; conversas espontâneas; e entrevistas semiestruturadas. Inicialmente foi feita revisão bibliográfica sobre o tema e leitura de trabalhos abordando experiências de organização de catadores e programas de coleta seletiva municipais. Em busca de identificar os principais atores ligados ao tema e problematizar os discursos de catadores e demais envolvidos na questão, foi realizada observação participante nos seguintes eventos: Festival Lixo e Cidadania, 2008 (Belo Horizonte - MG); $1^{\circ}$ Diálogos Negócios Inclusivos, 2009 (São Paulo-SP); e Seminário Reciclagem: metodologias sustentáveis para os resíduos e a inclusão social, 2010 (São Paulo SP). Houve também diversas conversas espontâneas com catadores do movimento nacional, membros de organizações de apoio aos catadores e profissionais da área de gestão de resíduos sólidos urbanos. Tais conversas foram de caráter informal, como primeira etapa exploratória. De forma paralela, foi feita análise de documentos pesquisados na internet, como leis, decretos e regulamentações, bem como de materiais recebidos nos eventos em que houve participação dos pesquisadores, como folders, textos e jornais informativos. No entanto, a análise desses materiais foi apenas de caráter complementar, uma vez que não se empreendeu uma análise documental estrita. Posteriormente, foram realizadas entrevistas em profundidade do tipo semiestruturada com dois catadores, lideranças do MNCR, com uma ex-superintendente de limpeza urbana de Belo Horizonte, que foi uma das responsáveis pela criação do Fórum Nacional Lixo e Cidadania (FNLC) e atuou no Ministério do Desenvolvimento Social e Combate à Fome (MDS) como secretária de Articulação para Inclusão Produtiva, e com uma ex-coordenadora do programa de coleta seletiva de Belo Horizonte, que também atuou no FNLC e no MDS em ações voltadas para a inclusão social e produtiva de catadores.

Em busca de contemplar o objetivo aqui proposto, inicialmente são apontadas as dificuldades e limitações na aplicação de modelos de formação de agenda produzidos em contextos diferenciados da realidade brasileira. Posteriormente é apresentada a abordagem de Múltiplos Fluxos, de John Kingdon (1995), adotada neste trabalho, apontando suas limitações para a análise da realidade investigada. Feito isso, é problematizado o processo pelo qual a inserção de catadores em programas de coleta seletiva alcançou a agenda governamental federal. Parte-se, em especial, da realidade local de Belo Horizonte, devido ao fato de que alguns profissionais da área de gestão de resíduos sólidos, algumas pessoas ligadas à Igreja Católica, gestores públicos e políticos que atuaram no município passaram a atuar no âmbito nacional em posições importantes, seja no governo federal e/ou em instâncias extrainstitucionais ligadas ao tema. Entretanto, é importante destacar que o processo de formação de agenda investigado não se originou exclusivamente de uma realidade local, mas de uma teia de relações de diversos atores e dinâmicas de diferentes regiões do país. Na última 
seção são apresentadas as considerações finais com algumas sugestões para aprofundamentos em estudos futuros.

Formação de Agenda Governamental: em Busca de Teorias que Ajudem a Analisar a Realidade Brasileira

Por que algumas questões entram na agenda de políticas públicas, enquanto outras são ignoradas? Como alguns temas se tornam problemas socialmente construídos e ganham a atenção de governos, sendo objeto de políticas públicas? Estes questionamentos são centrais nas discussões de definição de agenda governamental.

Em busca de explicar esses processos, no âmbito da literatura sobre políticas públicas, foram desenvolvidos vários modelos de definição de agenda, principalmente nos EUA, onde surgiu o estudo de políticas públicas enquanto área do conhecimento (SOUZA, 2006). Entre os modelos explicativos, destacam-se como principais e de maior uso nos estudos brasileiros, o de Múltiplos Fluxos, de John Kingdon (1995), o de Equilíbrio Pontuado, de Frank Baumgartner e Brian Jones (1993) e o de Coalizão de defesa, de Sabatier e Smith (WEIBLE, SABATIER e MCQUEEN, 2009). Cada modelo apresenta suas peculiaridades e diferenças, algumas delas bem acentuadas e até opostas (VIANA, 1996; SOUZA, 2006; CAPELLA, 2006).

$\mathrm{Na}$ adoção de qualquer modelo de análise de políticas públicas, formulado com base em realidades diferentes, faz-se necessário problematizar até que ponto ele ajuda a iluminar a realidade política, econômica e social do Brasil. Esse fator se torna ainda mais importante ao se considerar que a democracia brasileira ainda está em processo de consolidação. Como alerta Frey (2000), as características socioeconômicas e políticas de países em desenvolvimento, como o Brasil, não podem ser tratadas apenas como fatores institucionais e processuais específicos, sendo necessária uma adaptação dos instrumentos de análise de políticas públicas.

Em um contexto de instituições democráticas frágeis, de coexistência de comportamentos políticoadministrativos modernos e tradicionais, torna-se difícil usar os mesmos modelos de análise adotados para compreender estruturas já consolidadas ou com dinâmicas distintas de funcionamento. É imprescindível uma adaptação das abordagens de análise de políticas públicas às particularidades da situação política e institucional do país (FREY, 2000).

Considerando apenas as políticas públicas brasileiras de âmbito municipal, a análise por meio de tais modelos se torna ainda mais complexa, uma vez que existe uma imensa diversidade estrutural e institucional, devido à autonomia financeira, administrativa e política dos municípios, que engloba, por exemplo, o direito de cada um deles outorgar sua própria constituição local (FREY, 2000). Essa nova configuração ocorreu a partir da Constituição de 1988, que foi marcada pela descentralização ao definir um novo tipo de arranjo federativo, no qual houve transferência de decisões, atribuições e recursos aos estados e municípios (NOGUEIRA, 1997).

Não obstante os problemas e limitações da descentralização (ARRETCHE, 1996; MELO, 1996; NUNES, 1996; NOGUEIRA, 1997; SOUZA, 2002), o fato é que os governos subnacionais, principalmente os governos locais, obtiveram maior autonomia e maiores responsabilidades na provisão de políticas públicas. Entre as atribuições dos municípios está a responsabilidade pela gestão dos resíduos sólidos - hoje um dos principais problemas ambientais urbanos e um dos maiores desafios aos governos municipais, dada a complexidade que envolve a situação do lixo.

Também é complexa a utilização de tais modelos para o estudo de formulação de políticas públicas de "baixo para cima", como o caso destacado neste trabalho. Vale pontuar que experiências dessa natureza configuram diálogo com as discussões da gestão social, uma vez que nascem de debates e mobilizações de organizações da sociedade civil, os quais visam ganhar o espaço público e alcançar a agenda governamental. Em contextos em que organizações da sociedade civil em conjunto com uma rede de atores pressionam o poder público local para obter respostas diante de problemas sociais, bem como em situações nas quais a agenda de 
políticas públicas local alcança a agenda governamental nacional, os desafios se tornam ainda maiores quando se busca a compreensão de processos de formação de agenda. Além do caso que será problematizado neste trabalho, há exemplos como o Programa Um Milhão de Cisternas (P1MC), que, de uma iniciativa da Articulação para o Semiárido (ASA) - constituída de uma rede de organizações da sociedade civil - teve sua formulação em um projeto nacional de convivência com o semiárido por meio de construção de cisternas. Este projeto alcançou a agenda governamental nacional e se tornou um programa dentro da política de segurança alimentar do governo federal (TEODÓSIO, 2008).

Considerando os pontos abordados acima, e mediante uma análise prévia, optou-se por utilizar neste trabalho a discussão de Múltiplos Fluxos, de Kingdon (1995), uma vez que a abordagem traz elementos importantes à compreensão da experiência em questão, em que pesem suas limitações e problemas para analisar a realidade social investigada, que serão destacados no decorrer da análise. Como ressalta Saasa (2006, p. 220), "o analista não pode, invocando a precisão teórica, prender-se com excessiva rigidez a um modelo em particular, à custa de negligenciar aspectos importantes do ambiente em estudo". No tópico seguinte apresenta-se o modelo de Kingdon (1995) e suas limitações à análise da dinâmica investigada neste artigo.

\section{O Modelo de Múltiplos Fluxos, de John Kingdon}

O modelo de Kingdon (1995) é baseado em três fluxos ou dinâmicas do processo de formação de agenda: problemas, política e propostas de políticas públicas. Mas, antes de discutir cada um desses fluxos e suas relações, vale abordar os principais conceitos que Kingdon utiliza.

O autor faz uma clara distinção entre os dois processos pré-decisórios abordados em seu livro, a saber, a agenda e as alternativas. Os três tipos de agendas diferenciadas por Kingdon são: sistêmica, governamental e decisória. A agenda sistêmica refere-se à lista de assuntos que são, há um bom tempo, preocupação da sociedade de um determinado país, mas que, no entanto, não recebem e nem conquistaram ainda a atenção do governo. A agenda governamental consiste na lista de temas que são objeto de atenção por parte de autoridades governamentais e de seus assessores em um dado momento. Essa lista varia de acordo com os diferentes setores do governo. A agenda decisória, por sua vez, constitui-se da lista de temas dentro da agenda de governo que são encaminhados para deliberação (KINGDON, 1995; VIANA, 1996). Já as alternativas são outra etapa do processo pré-decisório, em que há uma especificação de alternativas na qual as escolhas são realizadas.

O primeiro fluxo do modelo é o dos problemas, no qual Kingdon (1995) aborda os meios pelos quais os atores tomam conhecimento de determinada situação e também as formas em que situações são consideradas problemas. Os meios podem ser indicadores, eventos-foco e retroalimentação (feedback). Os indicadores podem mostrar que existe uma situação, sua magnitude e apontar mudanças ocorridas e, desse modo, chamar a atenção das autoridades. No entanto, pode ocorrer a situação inversa, isto é, os indicadores serem produzidos depois que um tema entra na agenda governamental, como no caso da construção de indicadores sobre a questão racial no Brasil (CARDOSO, 2005). Os eventos-foco como, por exemplo, desastres, crises e acontecimentos marcantes podem chamar a atenção para algumas situações em detrimento de outras. Porém, os efeitos dos eventos podem ser passageiros se não forem acompanhados de uma percepção ou indicação de um problema social. Por fim, a retroalimentação de programas e projetos pode levar os atores governamentais a tomarem conhecimento de novas situações.

Kingdon (1995) destaca a diferença entre uma situação e um problema. Várias situações ou condições objetivas estão presentes no cotidiano, sendo toleradas e não consideradas como problemas sociais. $\mathrm{O}$ reconhecimento de problemas é um passo crítico para o estabelecimento de agendas. As possibilidades de um tema assumir lugar de destaque na agenda são maiores se for associado a um problema importante. Nesse processo, os empreendedores de políticas (policy entrepreneurs) têm um papel importante no convencimento 
de autoridades para que a demanda em questão ganhe importância na agenda governamental (KINGDON, 1995).

A relação entre condições objetivas (situação), problema e agenda governamental não é natural, nem tampouco direta. A existência de uma condição objetiva não é suficiente para colocá-la numa agenda governamental ou societária. Para uma condição objetiva se tornar problema, é necessário que a sociedade a reconheça como um problema social. Só quando um assunto é construído socialmente como um problema é que ele tem chance de entrar na agenda governamental. Para Fuks (2000, p. 80), "a emergência de questões na agenda pública explica-se mais em termos da dinâmica social e política do que dos atributos intrínsecos dos assuntos em disputa, ou seja, das 'condições reais' dos problemas em questão". O autor observa que a condição para que um determinado assunto se torne objeto de atenção social está no seu reconhecimento como assunto público.

Alguns problemas, no entanto, podem ser encarados pelo governo, por meio de inação, ou seja, são completamente ignorados. Outra circunstância possível é a retirada de um tema da agenda em virtude de a atenção governamental voltar-se para outro assunto; ou, ainda, porque as pessoas se frustram com o fracasso e se negam a investir mais tempo em uma causa perdida. Ocorre também de mudar a situação que chamou a atenção para o problema ou as pessoas se acostumarem com ele e lhe conferirem outro rótulo. Também novas prioridades podem surgir e questões anteriores serem relegadas (KINGDON, 1995).

O segundo fluxo abordado por Kingdon (1995) é o da política, que engloba elementos como mudança de governos e de membros do Congresso via eleições, tendências do ambiente nacional ou clima nacional, e grupos de interesse, que conseguem pressionar ou não o governo. Um novo governo, por exemplo, muda completamente a agenda ao enfatizar certos problemas ligados às suas configurações partidárias e ideológicas. $\mathrm{O}$ ambiente nacional pode ser conservador e resistente a certas propostas e mais aberto a outras em um dado momento. Por sua vez, grupos de interesse podem se opor a certas propostas de políticas públicas. $\mathrm{O}$ autor aponta que, na dinâmica da política, o consenso é formado via negociação e não via persuasão.

Os participantes ressaltados por Kingdon (1995) no processo são divididos em dois grupos - os participantes "visíveis" e os "invisíveis". Os atores visíveis são aqueles que recebem atenção da imprensa e do público, compreendem o presidente e seus assessores de alto escalão, importantes membros do Congresso, a mídia e atores ligados ao processo eleitoral, como partidos políticos e comitês de campanha. Já os atores invisíveis compreendem acadêmicos, burocratas de carreira e funcionários do Congresso. O último grupo de atores influencia na escolha de alternativas, enquanto os atores visíveis influenciam na formação da agenda, sendo destacada principalmente a influência do presidente (KINGDON, 1995).

Para o autor a combinação de vontade nacional com eleições é a formadora de agenda mais poderosa do que aquela criada por grupos de interesse. Kingdon (1995) argumenta que grupos de interesse raramente iniciam avaliações de propostas ou estabelecem agendas por si mesmos, sendo a atuação desses grupos direcionada mais no sentido de barrar e se opor a temas da agenda. Esse é um dos pontos problemáticos do modelo para a análise da realidade investigada neste trabalho. Kingdon (1995) dá pouca importância à influência da sociedade civil na formação da agenda, não menciona a influência de, por exemplo, movimentos sociais que demandam, do poder público, direitos, reconhecimento e posicionamento diante de problemas sociais. Esse ator social não pode ser negligenciado na análise da realidade brasileira, principalmente no exame de temas da agenda ligados a problemas decorrentes da desigualdade social.

Talvez a pouca importância dada por Kingdon (1995) à influência da sociedade civil decorra, além das peculiaridades da realidade estadunidense, dos casos analisados em seu trabalho e da sua visão de democracia representativa, como se pode observar no seguinte trecho: 
[...] pelo menos com relação ao estabelecimento da agenda, políticos eleitos e seus assessores são mais importantes do que funcionários públicos de carreira ou participantes que não fazem parte do governo. Para aqueles que buscam evidências do funcionamento da democracia, esse é um resultado encorajador. (p. 199). ${ }^{5}$

Este trecho evidencia uma predominância da concepção de democracia representativa, uma vez que exalta o papel de políticos eleitos e seus assessores na formação da agenda em detrimento de outros atores, como aqueles que não fazem parte do governo. No entanto, no contexto brasileiro ocorrem outras configurações na relação entre Estado e sociedade. A partir da década de 1990, houve no país uma proliferação de mecanismos de participação, como, por exemplo, os conselhos gestores de políticas públicas e os orçamentos participativos. Não isentas de problemas e limitações, tais experiências evidenciam novas formas de relação entre sociedade civil e Estado que não podem ser ignoradas. Vale ressaltar que tais dinâmicas não se restringem ao contexto brasileiro, Santos e Avritzer (2003), por exemplo, analisaram várias experiências de democracia participativa articulada com a democracia representativa em diferentes países do Sul, problematizando os diferentes processos na construção de democracias, com especificidades e características distintas em cada país.

O principal ponto crítico de inadequação e limitação do modelo para compreender a realidade pesquisada neste artigo refere-se ao fato de o modelo de Kingdon (1995) ser de "cima para baixo", enquanto o processo de formação de agenda analisado neste trabalho baseia-se numa experiência que ocorreu de "baixo para cima". Essa característica do modelo de Kingdon é claramente perceptível e está explícita no seguinte trecho: "[...] os papéis dos vários participantes na formulação de agendas podem ser definidos com bastante precisão por meio de um modelo claro, que funciona 'de cima para baixo', com os políticos eleitos situados no topo" (KINGDON, 1995, p. 199). ${ }^{6}$

Diante desse ponto crítico, pode parecer incongruente adotar esse modelo, mas, ainda assim, algumas dinâmicas apontadas nos três fluxos auxiliam em certa medida na compreensão do caso analisado. Todavia, as limitações e inconsistências do modelo para análise da experiência em estudo serão apontadas mais claramente na sessão seguinte.

O terceiro fluxo analisado por Kingdon (1995) é a dinâmica das políticas públicas, que se refere ao processo de surgimento e escolha de alternativas. O surgimento de alternativas é um processo desordenado de ideias que se colidem gerando novas ideias ou formam combinações e recombinações. Já o processo de escolha envolve critérios, padrões que norteiam a seleção, como, por exemplo, viabilidade técnica, congruência com os valores dos membros da comunidade de especialistas, antecipação de possíveis restrições - orçamentárias, aceitação da população e receptividade de políticos. Nesse processo os empreendedores de políticas também exercem um papel de articulação e convencimento em torno de alternativas possíveis.

Kingdon (1995) argumenta que os três fluxos - problemas, política e políticas públicas - possuem dinâmicas independentes, mas que, em alguns momentos, se unem. Por exemplo, um problema urgente ganha dimensão pública e uma proposta de política pública se associa a ele em um determinado momento com receptividade de diferentes atores políticos. Ou, então, uma mudança de governo pode gerar transformações de direção política e trazer novos problemas que se encaixam nessa nova conjuntura e, por sua vez, propostas já existentes podem se adequar a essa nova realidade. Nesse processo também podem ocorrer associações parciais, como soluções para problemas que não contam com receptividade política; propostas de políticas

\footnotetext{
${ }^{5}$ No original: "At least as far as agenda setting is concerned, elected officials and their appointees turn out to be more important than career civil servants or participants outside of government. To those who look for evidences of democracy at work, this is an encouraging result" (p.199).

${ }^{6}$ No original: "To describe the roles of various participants in agenda setting, a fairly straightforward top-down model, with elected officials at the top, comes surprisingly close to the truth" (p. 199).
} 
com receptividade em determinado momento político, mas que não possuem um problema que se adéque; ou ainda, política e problema necessitando de uma ação, mas com ausência de uma alternativa possível. A completa junção das três dinâmicas aumenta as chances de um tema entrar na agenda decisória.

O autor também trata da noção de janela de oportunidade para políticas públicas, que consiste em uma ocasião oportuna para que defensores de uma determinada causa ofereçam suas soluções ou chamem atenção para determinados problemas. As janelas são abertas por acontecimentos tanto na dinâmica dos problemas como na dinâmica da política. Desse modo, há janelas oriundas dos problemas e da política. Quando um novo problema surge, cria-se a oportunidade de proposição de soluções para ele. Por sua vez, na dinâmica da política, a eleição de novos representantes, uma mudança no clima nacional, ou mesmo um lobby poderoso podem criar oportunidades para que novos problemas e propostas ganhem espaço na dinâmica das políticas públicas. Entretanto, outros problemas e propostas até então existentes podem perder espaço na agenda. As janelas são escassas, pequenas e podem ser imprevisíveis (KINGDON, 1995).

Nesse processo os empreendedores de políticas (policy entrepreneurs) têm um papel fundamental. Geralmente são pessoas dispostas a investir tempo e recursos para promover certas políticas. Esses empreendedores podem ser políticos eleitos, funcionários públicos de carreira, lobistas, acadêmicos ou jornalistas. Kingdon (1995) aponta que esses atores são motivados por uma combinação de diversos elementos, como preocupação direta com certos problemas, busca de benefícios próprios, de reconhecimento, promoção de seus valores, prazer de participar, entre outros motivos. Eles atuam em três conjunturas, tentando colocar certos problemas no topo da agenda, promovendo determinadas propostas e estabelecendo conexões entre os três fluxos quando janelas de oportunidades são abertas. A presença de um empreendedor habilidoso aumenta consideravelmente as possibilidades de uma questão chegar ao topo da agenda (KINGDON, 1995).

Kingdon (1995) considera os três fluxos de forma independente, ou seja, para ele não existe uma lógica organizada em etapas. Desse modo, os participantes do processo não identificam primeiro um problema para depois buscarem uma solução. Pelo contrário, na maioria das vezes a defesa de soluções precede ao foco dos problemas. As agendas não são definidas para que depois se gerem as alternativas - normalmente estas últimas são elaboradas ao longo de anos, antes que uma oportunidade surja. O modelo de Kingdon (1995) é baseado no modelo de Garbage Can, de Cohen, March e Olsen (1972), no qual compreendem os processos de tomada de decisão e a dinâmica organizacional como anarquias organizacionais, em que um conjunto de opções estão a procura de problemas, temas procuram situações decisórias, soluções procuram por problemas e tomadores de decisão procuram por trabalho. Essas anarquias organizacionais seriam caracterizadas por três propriedades gerais: preferências problemáticas; tecnologias não claramente especificadas; e pela participação fluida (COHEN, MARCH e OLSEN, 1972).

Mas Kingdon (1995) ressalta que, além da imprevisibilidade presente no processo de formação de agenda, há também algum grau de padrão e previsibilidade em três fontes fundamentais: dentro de cada dinâmica; nos processos que estruturam as conexões; e nas restrições gerais sobre o sistema.

\section{Catadores de Recicláveis e Programas de Coleta Seletiva: da Agenda Local à Nacional}

Em situação de rua, submetidos a condições precárias de vida e ao desrespeito por parte da sociedade, os catadores iniciaram um processo de luta para mudar essa realidade. Esse processo ocorreu inicialmente em algumas capitais do país, como São Paulo, Belo Horizonte e Porto Alegre, por meio do trabalho desenvolvido por organizações da Igreja Católica.

Neste artigo destaca-se a experiência de Belo Horizonte, uma vez que atores que atuaram na capital mineira passaram a ocupar posições importantes no âmbito nacional e influenciaram no processo de inserção do tema na agenda federal. Além disso, vale destacar que a experiência de Belo Horizonte ganhou grande repercussão 
nacional e internacional, sendo considerada uma das mais exitosas do país; o que ajudou a legitimar em certa medida a forma de ação governamental adotada para a inserção de catadores. Entretanto, é importante frisar, desde já, que atores diversos, pessoas, organizações e outras realidades locais também influenciaram no processo. O caminho trilhado nesse trabalho, por sua vez, se deve às principais conexões e relações entre atores, reveladas durante a fase exploratória da investigação, que, com a realização de entrevistas semiestruturadas, se confirmaram ao mesmo tempo em que novas dimensões, atores e pessoas foram destacados no processo.

A dinâmica de organização de catadores de Belo Horizonte teve início quando algumas irmãs beneditinas da OAF migraram para a capital mineira e, por intermédio da Pastoral de Rua da Arquidiocese de Belo Horizonte, iniciaram, como em São Paulo, um trabalho com a população de rua que sobrevivia da cata de materiais no lixo (JACOBI e TEIXEIRA, 1997).

A Pastoral de Rua iniciou os primeiros contatos com esse grupo, que a princípio reagia de forma arredia, em virtude das situações de violência e opressão que estavam acostumados a sofrer por parte do poder público local. Os catadores eram vistos pela população e pelo poder público como "vagabundos" e "delinquentes" que sujavam a cidade, de modo que as políticas adotadas para a questão envolviam ações denominadas "operação limpeza", que os retiravam à força do centro da cidade (JACOBI e TEIXEIRA, 1997; DIAS, 2002; GONÇALVES, OLIVEIRA e SILVA, 2008; PEREIRA, 2011).

Diante desse contexto, a Pastoral começou a desenvolver um trabalho sociopedagógico com os catadores, buscando mostrar, por meio de práticas socioeducativas, a importância do trabalho que realizavam, estimulando-os a formar uma associação para lutarem por seus direitos. Esse processo ofereceu as bases para a constituição da ASMARE no ano de 1990 (JACOBI e TEIXEIRA, 1997; DIAS, 2002; GONÇALVES, OLIVEIRA e SILVA, 2008; PEREIRA, 2011).

A organização dos catadores iniciou-se com uma atuação reivindicatória junto ao poder público municipal durante a gestão do então prefeito Eduardo Azeredo (1990-1992), realizando intensa mobilização, por meio de atos públicos, ocupação de espaços para a futura triagem de recicláveis e protestos encaminhados à Câmara Municipal. Essa atuação buscava forçar o poder público a romper com uma postura de discriminação e violência (GONÇALVES, OLIVEIRA e SILVA 2008). Nesse processo, a Pastoral sensibilizou outros atores e os catadores passaram a contar, também, com o apoio de organizações da sociedade civil local, como a Associação Mineira de Defesa do Meio Ambiente (AMDA) e a Pastoral de Direitos Humanos. Além disso, conseguiram apoio de alguns membros da Câmara Municipal, entre eles o então vereador Patrus Ananias, do PT.

Esse processo de mobilização viabilizou em 1990, por ocasião da votação da Lei Orgânica do Município (constituição municipal), a inclusão de instrumentos para a implantação de uma futura coleta seletiva no município, com preferência por cooperativas de trabalho na realização da coleta e comercialização de materiais recicláveis (JACOBI e TEIXEIRA, 1997). Outra conquista dos catadores ocorreu em 1992, quando teve início a construção de um galpão para triagem de resíduos pela prefeitura (GONÇALVES, OLIVEIRA e SILVA, 2008).

A partir de 1993 a relação com o poder público muda de forma significativa. Patrus Ananias, eleito prefeito de Belo Horizonte por uma coligação de partidos de esquerda, viabiliza, em sua gestão, a criação do programa de coleta seletiva municipal, firmando um convênio com a Asmare. Entre os membros da equipe da nova administração municipal, Heliana Kátia Tavares, que antes apoiava os catadores como militante de uma ONG ambiental, foi nomeada superintendente da autarquia de Limpeza Urbana de Belo Horizonte (SLU).

Foi firmado um convênio entre prefeitura, Pastoral de Rua e Asmare. As atribuições do poder público consistiam em criar as condições necessárias ao funcionamento da associação, tais como: prover toda a estrutura logística e operacional de suporte ao trabalho dos catadores, incluindo os galpões de triagem, 
implantação de contêineres para recebimento de materiais separados pela população, caminhões para a coleta dos recicláveis; assessoria no processo de capacitação dos catadores associados, por meio de trabalho conjunto entre a Secretaria de Desenvolvimento Social e a SLU; e repasse de recursos financeiros mensais para a manutenção das instalações. Também coube à prefeitura divulgar a coleta seletiva e mostrar à população a importância do trabalho da Asmare, ressaltando os benefícios ambientais, sociais e econômicos decorrentes dessas atividades. A Pastoral de Rua ficou responsável pelo cumprimento de todas as obrigações assumidas pela Associação, apoiando os catadores em seu trabalho e organização. A Asmare, por sua vez, responsabilizou-se pela realização da coleta de recicláveis, pela manutenção do galpão, pela organização do cadastro e identificação dos associados, além de buscar ampliar a presença da Associação por intermédio de núcleos de trabalho em pontos estratégicos da cidade, assim como zelar pelo bom andamento de todo o trabalho (JACOBI e TEIXEIRA, 1997; DIAS, 2002).

A forma como é concebido um problema social ou a categoria em que é inserido influencia o tratamento que lhe é dado mediante políticas públicas, como ressaltam Kingdon (1995) e Fuks (2000). Em Belo Horizonte, quando os catadores eram vistos como "vagabundos e delinquentes" que sujavam o centro, as ações adotadas eram de repressão e violência (JACOBI e TEIXEIRA, 1997; DIAS, 2002; GONÇALVES, OLIVEIRA e SILVA, 2008). Já a partir de 1993, o problema passou a ser concebido da lógica da necessidade de inclusão social desse grupo, sendo adotadas ações inclusivas no âmbito do programa de coleta seletiva.

A inserção da questão na agenda governamental local teve como principais atores a Pastoral de Rua, os catadores organizados por meio da Asmare, a AMDA, representada por sua presidenta Heliana Kátia Tavares - posteriormente integrante da burocracia estatal municipal - e um membro do legislativo local, o vereador Patrus Ananias, eleito, em seguida, prefeito de Belo Horizonte. Embora o modelo de Kingdon (1995) tenha sido concebido para análise da formação de agenda no âmbito federal, em analogia ao âmbito local, os atores da sociedade civil exerceram forte influência na formação da agenda, em contraposição à pouca importância dada por Kingdon (1995) aos atores extrainstitucionais.

O convênio com o poder público ofereceu as bases para o desenvolvimento da Asmare e para o crescimento da organização, tendo a associação se tornado referência na unidade federativa e no país. O convênio entre Asmare e poder público se mantém até hoje, passando por algumas mudanças e adequações. A experiência da Associação levou a um processo de organização dos catadores em âmbito municipal.

É importante apontar que nos anos seguintes foram desenvolvidas outras experiências de associações e cooperativas de catadores atuando em conjunto com o poder público em programas de coleta seletiva municipais em diferentes regiões do país. Vale ressaltar que esse processo não foi simples e nem linear, mas, sim, marcado por conflitos sociais e dinâmicas específicas - em algumas cidades a relação do poder público com os catadores ainda é de repressão e violência.

Na década de 1990, começou a ganhar repercussão pública a situação precária de milhares de pessoas, inclusive crianças, que sobreviviam da cata de materiais em lixões. Diante dessa situação de calamidade em vários lixões do país, em 1998 foi criado o Fórum Nacional Lixo e Cidadania (FNLC) por uma iniciativa do United Nations Children's Fund (UNICEF) com os seguintes objetivos: erradicar o trabalho de crianças e adolescentes em lixões; estimular a inserção social e econômica de catadores em programas de coleta seletiva; e mudar a forma de destinação do lixo no país, eliminando os lixões e adotando aterros sanitários. O Fórum era coordenado por uma secretaria executiva composta por: representantes do UNICEF, entre eles Heliana Kátia Tavares, que passou a ser gestora do programa após o término do governo Patrus Ananias em 1996; do Ministério do Meio Ambiente; do Ministério Público Federal; da Secretaria Especial de Desenvolvimento Urbano da Presidência da República (SEDU); da Caixa Econômica Federal; da Fundação Nacional de Saúde (FUNASA); e da ONG Missão Criança. Posteriormente foram criados fóruns estaduais Lixo e Cidadania em 23 estados da federação. Fóruns municipais também foram constituídos e se multiplicaram pelo país. A iniciativa do UNICEF contribuiu para trazer à discussão pública a situação precária daqueles que sobrevivem da cata de recicláveis no lixo. 
No decorrer da década de 1990 e nos anos 2000, as experiências de cooperativas e associações de catadores se espalharam pelo país, formando a base inicial do que viria a ser o Movimento Nacional dos Catadores de Materiais Recicláveis (MNCR). O MNCR foi criado em meados de 1999 durante o $1^{\circ}$ Encontro Nacional de Catadores de Papel, realizado em Belo Horizonte, sendo formalizado em junho de 2001 durante o $1^{\circ}$ Congresso Nacional dos Catadores de Materiais Recicláveis, em Brasília. Esse congresso contou com cerca de 1700 participantes, entre catadores, técnicos e assistentes sociais de dezessete estados brasileiros, e mais 3000 participantes da Marcha Nacional da População de Rua. Durante o evento foi formulada a "Carta de Brasília", um documento com reivindicações e propostas à sociedade e ao poder público. Na carta foi destacada a necessidade de convênios para a destinação de recursos e apoio a empreendimentos de catadores; inclusão deste grupo no Plano Nacional de Qualificação Profissional; implantação em nível nacional de uma política de coleta seletiva baseada em um modelo de gestão integrada de resíduos sólidos; e erradicação dos lixões, oferecendo condições de trabalho e renda para as famílias que neles vivem.

O Movimento Nacional se constitui em um mecanismo de pressão dos catadores sobre o governo federal, bem como sobre diferentes esferas de governo. Uma das primeiras conquistas, ainda no governo Fernando Henrique Cardoso, foi o reconhecimento, em 2002 da ocupação "catador de material reciclável" pelo Código Brasileiro de Ocupações. O reconhecimento da ocupação no CBO exerceu uma função simbólica e deu visibilidade pública ao catador, já que muitas vezes sua atividade não é reconhecida socialmente pela sociedade (PEREIRA, 2011).

O FNLC e o MNCR demandavam do poder público nas diferentes esferas de governo, sobretudo na federal, o reconhecimento e a construção de políticas públicas voltadas à inserção de catadores em programas de coleta seletiva e à eliminação dos lixões no país. Esses atores extrainstitucionais buscavam colocar essa questão na agenda de políticas públicas. Embora Kingdon (1995) aponte que a atuação dos grupos de interesse consiga apenas bloquear a entrada de um tema na agenda e não o inserir, no caso analisado a dinâmica foi diferente. A atuação do FNLC e do MNCR não pode ser negligenciada no entendimento desse processo, e a abordagem de Kingdon (1995) é limitada na problematização dessas dinâmicas entre Estado e sociedade civil no contexto brasileiro.

Os catadores conquistaram alguns avanços durante o governo Lula (2003-2010) em termos de ações públicas de inclusão social e produtiva do segmento. Uma das primeiras foi a criação do Comitê Interministerial de Inclusão Social de Catadores (CIISC), em setembro de 2003, por meio de decreto presidencial. O Comitê é formado pelos seguintes órgãos do governo federal: MDS; Ministério das Cidades; Ministério do Meio Ambiente (MMA); Ministério do Trabalho e Emprego (MTE); Ministério de Ciência e Tecnologia (MCT); Ministério da Educação (MEC); Ministério da Saúde (MS); Ministério do Desenvolvimento, Indústria e Comércio (MDIC); Secretaria Especial de Direitos Humanos da Presidência da República (SEDH); Casa Civil da Presidência da República; Ministério da Previdência Social; Ministério de Minas e Energia; Caixa Econômica Federal; Banco Nacional de Desenvolvimento Econômico e Social (BNDES), Banco do Brasil, Petrobras e Eletrobrás (CIISC, 2010). Por meio do Comitê Interministerial são apoiadas ações voltadas aos catadores de materiais recicláveis, como o edital do BNDES para disponibilização de recursos a cooperativas e associações, o apoio da Petrobras à rede de organizações de catadores, a disponibilização pelo Ministério das Cidades do Programa PAC-Resíduos Sólidos, e doação de recursos financeiros da Fundação Nacional de Saúde e MTE, em parceria com a Fundação Banco do Brasil (FBB), a organizações de catadores de todo o país.

A ex-superintendente de limpeza urbana de Belo Horizonte relatou que, após a criação do Comitê, o FNLC esvaziou-se, uma vez que boa parte dos integrantes do fórum, que representava a sociedade civil, foi trabalhar no governo federal em ministérios ligados diretamente ao tema ou com interfaces. Desse modo, passaram a participar de reuniões do Comitê representando os ministérios e não mais como representantes da sociedade civil no âmbito do FNLC. Já aqueles integrantes que não eram do governo começaram a ser convidados a reuniões do CIISC como o MNCR, o UNICEF, o Compromisso Empresarial para a Reciclagem (CEMPRE), entre outros. A ex-coordenadora do programa de coleta seletiva da PBH também reforçou esse acontecimento em sua narrativa. Essa mudança de papéis de representantes do FNLC, que passaram a ocupar 
cargos do executivo federal, denota novas implicações na relação entre governo e sociedade civil. Esse aspecto merece um aprofundamento em estudos futuros, principalmente na discussão de quais desdobramentos tal processo gerou na construção de políticas públicas para os catadores, começando pela inserção do tema na agenda.

Com a criação do MDS, Patrus Ananias foi convidado a assumir o novo ministério. O MDS foi criado para integrar e desenvolver as políticas sociais do governo Lula, estabelecendo relações com organizações da sociedade civil e movimentos sociais, desse modo se tornou alvo de demandas sociais por parte da sociedade civil. Como ressalta Fucks (2000, p. 81), "[...] a existência de agências governamentais dedicadas à solução de um determinado problema incentiva a formulação e o encaminhamento de demandas difusas em termos adequados ao perfil do problema tal como definido institucionalmente".

Nesse processo de estruturação do MDS, Heliana Kátia Tavares foi convidada por Patrus Ananias a integrar o quadro de servidores públicos e se tornou secretária da Secretaria de Articulação para Inclusão Produtiva (SAIP). Passou a coordenar o CIISC e a construir parcerias para o desenvolvimento de ações de apoio aos catadores. Estes dois atores exerceram um papel importante na formação da Asmare e da parceria com o poder público local no programa de coleta seletiva de Belo Horizonte, chegaram aos quadros de gestores públicos do governo federal e continuaram a desenvolver ações ligadas à questão dos catadores. Os dois atores tiveram um papel fundamental nesse processo, sobretudo Heliana Tavares, e podem ser considerados empreendedores de políticas (KINGDON, 1995).

No âmbito do MDS foram desenvolvidas ações de inclusão socioprodutiva de catadores com o objetivo de incentivar os municípios a criar programas de coleta seletiva e apoiar cooperativas e associações de catadores. Essas ações foram articuladas com o Decreto presidencial 5.940/06, que prevê que todas as repartições públicas da administração direta ou indireta devem fazer coleta seletiva e doar os materiais para cooperativas de catadores. E também com a Lei 11.445/07, que altera a Política Nacional de Saneamento, permitindo que as administrações públicas contratem com dispensa de licitação as organizações de catadores de materiais recicláveis para a prestação de serviços de coleta seletiva, possibilitando dessa forma, a sua remuneração.

Entre as ações voltadas para os catadores desenvolvidas no MDS, inserem-se: o convênio (2004-2007) firmado entre a Cáritas Brasileira e o MDS, por meio da Secretaria Nacional de Assistência Social (SNAS), para a implantação da Coleta Seletiva Solidária na Esplanada; convênio com a OAF para capacitação de lideranças, fortalecimento do Movimento Nacional de Catadores e estudo do custo do posto de trabalho do catador; pesquisa para quantificação e caracterização da população em situação de rua das capitais e principais cidades brasileiras; edital da UNESCO para projetos de apoio à organização dos catadores e à população de rua, visando ao fortalecimento institucional dos catadores, propiciando encontros nacionais, articulações estaduais e capacitações; projeto BID/FUMIN, de apoio à organização de cadeias produtivas em comunidades de catadores, com o desenvolvimento de atividades que promovam a integração da família na comunidade, assim como o incentivo à melhoria das condições habitacionais; criação do Fórum Participa, um fórum permanente de articulação de parcerias, voltado para discussões de geração de trabalho e renda, organizado pela SAIP e que conta com representantes da sociedade civil e de empresas públicas e privadas. Neste fórum, a Fundação Avina atua no fortalecimento do MNCR e na integração com os movimentos da América Latina.

Durante o evento Expocatadores 2009, realizado pelo MNCR, contando com a presença do ex-presidente Lula, do ex-ministro Patrus Ananias, de outros ex-ministros e autoridades estatais, foram assinados documentos visando implantar os seguintes projetos e iniciativas: protocolo para implantação do Plano Nacional de Coleta Seletiva, com a Eletrobras, BNDES e Itaipu Binacional; projeto de fortalecimento das cooperativas com a FBB, com verba da Secretaria de Economia Solidária e do Ministério do Trabalho; contratos de concessão de colaboração financeira não reembolsável, para aumentar a capacidade produtiva de quatro cooperativas, assinado com o BNDES; termo de cooperação mútua entre a Fundação Nacional de Saúde, o MNCR e cooperativas; e acordo de cooperação para implementação do Programa Cata Ação. Além 
dessas ações de apoio aos catadores, um considerável avanço foi a aprovação da Política Nacional de Resíduos Sólidos (PNRS), em 2010. A Política prevê a integração de catadores aos processos de coleta seletiva, cabendo aos municípios a elaboração de Planos de Gestão Integrada de Resíduos Sólidos. Além disso, a PNRS institui princípios como o do poluidor pagador e da logística reversa. Também aponta a implantação de incineradores de resíduos como solução ambientalmente adequada, o que, entretanto, é fortemente criticado pelo MNCR e manifestado no pedido de veto ao artigo que permite a realização da incineração - solicitação que não foi acatada pelo ex-presidente. Um catador, atualmente liderança do MNCR, destacou que a preocupação do movimento é que, com a implantação de incineradores nos municípios, o catador corra o risco de ser excluído do processo ao perder o acesso à sua fonte de trabalho e renda, já que alguns resíduos recicláveis também poderão ser incinerados.

Considerando o contexto e os processos abordados acima, pode-se perceber que a definição da situação dos catadores como um problema deu-se por meio de construções sociais. Como ressalta Fucks (2000), os problemas são construídos muito mais pela dinâmica sociopolítica, que envolve a mobilização da atenção e a compreensão pública dos assuntos, do que pelas condições objetivas das questões. É importante apontar que a recuperação de materiais extraídos do lixo é uma atividade milenar: desde os tempos antigos, os destituídos obtinham sua sobrevivência das sobras da sociedade (DIAS, 2002). A atividade de catação no Brasil e a sobrevivência de milhares de pessoas por meio do lixo já vêm ocorrendo há muitas décadas. Em Belo Horizonte, por exemplo, a catação de lixo remonta desde o final da década de 1930 (DIAS, 2002). No entanto, somente nas duas últimas décadas a atividade ganhou atenção pública e reconhecimento como um problema social.

Os atores governamentais locais foram os primeiros a tomar conhecimento da situação, concebendo-a como um problema, porém, de formas distintas. Em Belo Horizonte, por exemplo, quando vistos como "vagabundos" e "delinquentes", os catadores foram alvo de "políticas higienistas". Já quando vistos como trabalhadores em condições degradantes de sobrevivência, a resposta governamental foi buscar inseri-los em um programa de coleta seletiva, oferecendo todo o apoio necessário. Esta última forma foi construída por meio de mobilizações sociais e protestos articulados de organizações de catadores e outras organizações da sociedade civil que apoiam esse grupo. Por sua vez, o problema alcançou a agenda governamental federal por intermédio de situações de mobilização da sociedade civil, sobretudo do FNLC e do MNCR, e também pela obtenção de respostas no âmbito de governos locais. De forma diferente do que Kingdon (1995) aponta, a sociedade civil atuou para colocar o tema na agenda valendo-se de mobilizações sociais, protestos e reivindicações, bem como de articulações com o poder público.

A construção social em torno desse problema é carregada de grande teor moral e de crenças, já que lida com questões de pobreza, desrespeito, falta de condições dignas de vida, humilhação, negação de direitos humanos. Envolve também elementos da problemática ambiental, que estão ligados à qualidade de vida das pessoas e à sobrevivência da humanidade no longo prazo. Além disso, a questão ambiental tem recebido grande destaque e atenção pública nas últimas décadas. No entanto, o modelo de Kingdon (1995) não aborda esses elementos ligados à construção social de problemas.

Com a mudança de governo em 2003, uma das características foi uma maior abertura e diálogo do governo Lula com a sociedade civil - traços do histórico de relações do PT com movimentos sociais. Além disso, a agenda governamental posta pelo governo Lula foi voltada para políticas sociais, como, por exemplo, os programas Fome Zero, Bolsa Família, Prouni, entre outros. Soma-se a isso um ambiente nacional favorável e com grandes expectativas em torno das políticas públicas do novo governo, sobretudo aquelas voltadas para questões sociais. Em suma, o fluxo da política era favorável e abria oportunidades à inserção de temas na agenda, como a inclusão produtiva e social de catadores. E o presidente, um ator de forte influência, como destaca Kingdon (1995), mostrou-se totalmente receptivo e também influenciou na inclusão do tema na agenda.

Heliana Kátia Tavares relatou que o ex-presidente assumiu o compromisso de, em sua gestão, desenvolver políticas voltadas à inclusão social e produtiva de catadores. Ela narrou que Lula, ao visitar um aterro, viu 
uma pessoa comendo um pedaço de melancia podre, o que o sensibilizou muito. Conta, também, situações dos bastidores de elaboração de políticas públicas que reforçam o compromisso e o envolvimento pessoal de Lula para melhorar as condições dos catadores. Seu relato é de que o presidente não aprovou a Lei Nacional de Saneamento, em 2007, por considerar que esta não abordava os catadores da forma como desejava. Solicitou que a refizessem de modo a prever melhores condições e possibilidades para o desenvolvimento dos catadores. Vale ressaltar também o "Natal do Lula com os catadores", realizado anualmente em São Paulo, desde 2003.

Além de Lula, a ex-superintendente apontou o papel desenvolvido por Gilberto Carvalho, então chefe de gabinete do ex-presidente. Por ser uma pessoa ligada à Igreja Católica, aos movimentos sociais e ao MNCR, sempre apoiou os catadores. A entrevistada destacou que ele era a "porta de entrada" do movimento nacional dos catadores no governo federal.

Quanto à dinâmica de propostas de políticas públicas, a principal alternativa veio com experiências exitosas no âmbito de governos locais, isto é, a inserção de catadores em programas de coleta seletiva com o apoio do poder público local. No entanto, diante dos desafios em que estão inseridos os catadores, apenas tal alternativa não é suficiente. Assim, buscam-se possibilidades de maior inserção destes trabalhadores nas diferentes cadeias produtivas da reciclagem, como a formação de redes de cooperativas e unidades fabris de beneficiamento de recicláveis. A primeira fábrica de beneficiamento de plásticos de catadores da América Latina, da rede Cataunidos de Minas Gerais, foi financiada por organizações integrantes do Comitê Interministerial. É importante destacar que as políticas desenvolvidas, sejam elas no âmbito local ou no nacional, são voltadas para catadores organizados em associações e cooperativas, no entanto, a maioria dos catadores no país encontra-se desorganizada, trabalhando individualmente nas ruas ou em lixões, ficando assim à margem da margem. Além disso, considerando a quantidade de resíduos sólidos produzidos no Brasil, ainda se recicla muito pouco e, por sua vez, as dificuldades e os custos para a disposição em aterros sanitários aumentam progressivamente. Ou seja, ainda não existe uma alternativa que dê conta da magnitude do problema da gestão dos resíduos sólidos e da inserção efetiva dos catadores nesse processo.

No caso analisado podem ser identificados dois atores principais que atuaram como "empreendedores de políticas": Patrus Ananias e Heliana Kátia Tavares. O primeiro, tanto em âmbito municipal quanto federal, exerceu influência na forma de conceber o problema social a que os catadores estão submetidos, sendo um ator "visível" conforme classificação de Kingdon (1995). Enquanto vereador em Belo Horizonte, tinha ligação estreita com movimentos sociais e apoiou a luta dos catadores. Ao se tornar prefeito, criou o programa de coleta seletiva e estabeleceu um convênio com a Asmare. Como ministro do MDS obteve maior visibilidade e capacidade de influência para colocar o tema na agenda governamental federal. Por sua vez, Heliana Tavares também exerceu grande influência na concepção do problema e em sua inserção na agenda - inicialmente em âmbito local, como militante de ONG ambientalista e como superintendente da SLU. Ao longo de sua trajetória profissional, tornou-se especialista em gestão de resíduos sólidos, contribuindo na criação do Fórum Nacional Lixo e Cidadania, em 1998, como representante do UNICEF. Em 2004, com a criação do MDS, foi convidada a integrar o quadro de funcionários, vindo a ocupar os cargos de chefe de gabinete do ministro, secretária executiva adjunta e de secretária da SAIP até 2007, quando se desvinculou do MDS. Atuaram, assim, como empreendedores de políticas habilidosos que souberam aproveitar as janelas de oportunidade que surgiram.

Em certa medida, houve a junção dos três fluxos: um problema que ganhou reconhecimento público, um ambiente político favorável à entrada de questões como essa na agenda e uma alternativa ao problema que se apresentou viável e com resultados comprovados - inclusão de catadores em programas de coleta seletiva -, mas que não dá conta totalmente das diferentes dimensões do problema, como, por exemplo, a melhoria das condições de trabalho de catação. Na realidade, ainda não há uma alternativa que consiga dar conta dos desafios em que os catadores estão inseridos, mas a inserção desse grupo em programas de coleta seletiva municipais é um primeiro passo necessário. 
As janelas de oportunidades foram abertas tanto na dinâmica dos problemas quanto na da política, e aproveitadas por empreendedores de políticas habilidosos. Nesse processo a sociedade civil teve um papel fundamental, principalmente o FNLC e o MNCR.

\section{Considerações finais}

A análise aqui empreendida é uma possibilidade de reflexão, na qual alguns aspectos precisam ser aprofundados para melhor compreensão dessa dinâmica de formação de agenda, bem como outras discussões teóricas poderiam ser incorporadas para subsidiar a análise. Quanto à abordagem teórica adotada, é importante pontuar algumas críticas e observações. O modelo de Múltiplos Fluxos, de Kingdon (1995), não consegue abarcar algumas questões da realidade investigada, bem como certos aspectos específicos do contexto brasileiro. O modelo não concebe um processo de formação de agenda de "baixo para cima" e também não aborda a influência de atores extrainstitucionais na agenda, como organizações da sociedade civil. Desse modo não dá conta de explicar as complexas relações entre Estado e sociedade civil na realidade brasileira. Afinal, até que ponto as organizações da sociedade civil influenciam na formação da agenda de políticas públicas?

Kingdon (1995) também não aborda a questão de valores e crenças na formação de problemas sociais. Como visto neste texto, a convicção de alguns atores políticos em cargos estratégicos na administração pública, e que antes apoiavam a causa dos catadores em organizações da sociedade civil, foi decisiva para que o tema fosse incluído na agenda de políticas públicas tanto no âmbito local como no nacional.

O modelo proposto pelo autor não aprofunda a análise dos processos de construção social de problemas. Como são construídos e interpretados os diferentes problemas sociais que podem vir a ser objeto de ações públicas? Indagações como estas não integram o escopo do trabalho de Kingdon, mas merecem maior aprofundamento, uma vez que a forma como é interpretado um problema influenciará tanto no grau de importância que lhe será dado pelos diferentes interesses sociais envolvidos, como também no que se refere ao tratamento que será dado pelo governo.

Em suma, o modelo de Kingdon, embora bastante disseminado na análise de políticas públicas, não contempla a participação da sociedade civil, nem tampouco as dinâmicas de conflito social existentes nas sociedades e as próprias dinâmicas de luta no interior dos governos.

Em relação à participação de organizações da sociedade civil, as discussões elaboradas no âmbito da gestão social poderiam trazer subsídios para análises das relações entre Estado e sociedade civil na construção e provisão de políticas públicas. A gestão social, ao se inserir tanto no nível societário quanto organizacional (FRANÇA FILHO, 2007), traz interessantes elementos para a discussão dessas dinâmicas.

Outro caminho interessante para o exame de casos como o problematizado neste trabalho seria usar as teorias da sociologia dos problemas sociais, uma vez que contribuiria para compreender os processos de construção de problemas sociais (LENOIR, 1996). As discussões sobre movimentos sociais que, por sua vez, têm interfaces com a gestão social, também poderiam oferecer subsídios para a compreensão da influência da sociedade civil na agenda e construção de políticas públicas.

No caso analisado é fundamental reconhecer o papel de diferentes organizações da sociedade civil, como o MNCR, que abarca várias associações e cooperativas de catadores do país, o FNLC, os fóruns estaduais e municipais Lixo e Cidadania e as demais organizações que compõem a rede de apoio aos catadores. Esses atores buscam influenciar a construção de políticas públicas que promovam o acesso a direitos.

A luta dos catadores por melhores condições de vida e trabalho e a gradativa incorporação dessa questão em políticas públicas abrange muitos desafios, uma vez que a gestão dos resíduos sólidos envolve diversos 
atores com interesses distintos. A questão do lixo nos leva a repensar os padrões de consumo e produção da sociedade e seus impactos socioambientais. No entanto, o lixo, muitas vezes, é tratado apenas como um novo negócio, no qual alguns segmentos da sociedade, principalmente aqueles com maior poder econômico e político, acabam se beneficiando. É imprescindível a construção de políticas públicas que possibilitem o exercício efetivo de direitos por parte de milhares de catadores do país, que estão em situação de pobreza e vulnerabilidade social. Há que se reconhecer os avanços nos últimos anos em termos de reconhecimento público da questão e de construção de políticas públicas voltadas ao tema. Mas ainda há muito que ser feito, já que a gestão dos resíduos sólidos é um grande desafio, não apenas ambiental, econômico, tecnológico ou social, mas sobretudo político, visto que envolve a escolha de que tipo de sociedade queremos ser - se de fato vamos caminhar rumo à uma sociedade sustentável, justa e democrática.

\section{Referências}

ARRETCHE, M. T. S. Mitos da descentralização: mais democracia e eficiência nas políticas públicas? Revista Brasileira de Ciências Sociais, n. 31, ano 1, 1996.

BAUMAN, Z. Vidas desperdiçadas. Tradução de Carlos Alberto Medeiros. Rio de Janeiro: J. Zahar, 2005.

BAUMgartner, F. R; JONES, B. D. Agendas and instability in American politics. Chicago: University of Chicago Press, 1993.

BOSI, A.P. A organização capitalista do trabalho informal: o caso dos catadores de recicláveis. RBCS, v. 23, n. 67, 2008.

CALMON, P. C. P.; COSTA, M. M. Análise de políticas públicas no Brasil: estudos sobre a formação da agenda governamental. In: ENCONTRO ANUAL DA ANPAD, 31, 2007, Rio de Janeiro. Anais. Rio de Janeiro, p.1-16, 2007.

CAPELLA, A. C. N. Perspectivas teóricas sobre o processo de formulação de políticas públicas. BIB, Revista Brasileira de Informação Bibliográfica em Ciências Sociais, v. 61, p. 20-40, 2006.

CARDOSO, N. Instituto Steve Biko - juventude negra mobilizando-se por políticas de afirmação dos negros no ensino superior. Dissertação (Mestrado em Educação e Contemporaneidade) - Salvador (BA), Universidade Estadual da Bahia, 2005.

CIISC - COMITÊ INTERMINISTERIAL DE INCLUSÃO SOCIAL DE CATADORES DE MATERIAIS RECICLÁVEIS. Relatório, Secretaria Executiva do CIISC. Brasília, maio de 2010.

COHEN, M. D.; MARCH, J. G., OLSEN, J. P. A garbage can model of organizational choice. Administrative Science Quarterly, vol. 17, p. 1-25, 1972.

DIAS, S. M. Lixo e Cidadania: os impactos da política de resíduos sólidos de Belo Horizonte no mundo do trabalho do catador da ASMARE. In: ENCONTRO ANUAL DA ASSOCIAÇÃO BRASILEIRA DE ESTUDOS POPUlACIONAIS, 13., Ouro Preto, 2002. Anais... Ouro Preto, nov. 2002, p. 1-25. Disponível em: <http://www.abep.nepo.unicamp.br/docs/anais/pdf/2002/GT_MA_ST37_Dias_texto.pdf >Acesso em: 26 jun. 2009.

FRANÇA FILHO, G. C. Definindo Gestão Social. In: ENCONTRO NACIONAL DE PESQUISADORES EM GESTẪO SOCIAL, 1. Juazeiro do Norte-CE, 2007, p.1-8.

FREY, K. Políticas públicas: um debate conceitual e reflexões referentes à prática da análise de políticas públicas no Brasil. Planejamento e políticas públicas, n. 21, 2000.

FUKS, M. Definição da agenda, debate público e problemas sociais: uma perspectiva argumentativa da dinâmica do conflito social. BIB, Revista Brasileira de Informação Bibliográfica em Ciências Sociais, n. 49, p. 79-94, 2000. 
GONÇALVES, J. A.; OlIVEIRA, F. G.; SILVA, D. T. A. Dezoito anos catando papel em Belo Horizonte. Estud. av.,

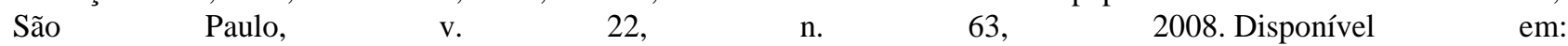
<http://www.revistasusp.sibi.usp.br/scielo.php?script=sci_arttext\&pid=S0103-0142008000200016\&lng=pt\&nrm=iso > Acesso em: 26 jun. 2009.

INSTITUTO BRASILEIRO de Geografia e Estatística. Pesquisa nacional de saneamento básico - 2008 . Rio de Janeiro: IBGE, 2010.

JACOBI, P. R.; TEIXEIRA, M. A. C. Criação do capital social: o caso da ASMARE - Associação dos Catadores de Papel, Papelão e Material Reaproveitável de Belo Horizonte. Cadernos Gestão Pública e Cidadania, v. 2, 1997. São Paulo: FGV-EAESP, 1997.

.; VIVEIROS, M. Da vanguarda à apatia, com muitas suspeitas no meio do caminho - gestão de resíduos sólidos domiciliares em São Paulo entre 1989 e 2004. In: JACOBI, P. (Org.). Gestão compartilhada de resíduos sólidos no Brasil - Inovação com inclusão social. São Paulo: Annablume, 2006. v. 1, p. 17-64.

KINGDON, J. W. Agendas, alternatives, and public policies. New York: Harper Collins, 1995.

LAYARGUES, P. O cinismo da reciclagem: o significado ideológico da reciclagem da lata de alumínio e suas implicações para a educação ambiental. In: LOUREIRO, F.; LAYARGUES, P.; CASTRO, R. (Org.) Educação ambiental: repensando o espaço da cidadania. São Paulo: Cortez, 2002. p. 179-220.

LEAL, A. C.; GONÇALVES, M. A.; THOMAZ JÚNIOR, A. A reinserção do lixo na sociedade do capital: Uma contribuição ao entendimento do trabalho na catação e na reciclagem. In: THOMAZ JÚNIOR, A. Dinâmica geográfica do trabalho no século XXI: (Limites Explicativos, Autocrítica e Desafios Teóricos). Presidente Prudente, São Paulo: [s/n], 2009.

LENOIR, R. Objeto sociológico e problema social. In: CHAMPAGNE, P.; LENOIR, R.; MERLLIÉ, D.; PINTO, L. Iniciação à prática sociológica. Tradução: João de Freitas Teixeira. Petrópolis, RJ: Vozes, 1996.

MELO, M. Crise federativa, guerra fiscal e hobbesianismo municipal: efeitos perversos da descentralização? Revista São Paulo em Perspectiva, v. 10, n. 3, 1996.

NOGUEIRA, M. A. A dimensão política da descentralização participativa. São Paulo em Perspectiva, v. 11, n. 3, p. 9$19,1997$.

NUNES, E. Poder local, descentralização e democratização: um encontro difícil. São Paulo em Perspectiva, v. 10 , n. 3, 1996.

PEREIRA, M. C. G. Luta por reconhecimento e desigualdade social: uma análise da experiência dos catadores da Asmare em Belo Horizonte (MG). Dissertação (Mestrado em Administração Pública e Governo) - FGV-SP, 2011.

SAASA, O. A formulação da política pública nos países em desenvolvimento: a utilidade dos modelos contemporâneos de tomada de decisão. In: SARAVIA, E.; FERRAREZI, E. (Org.). Políticas públicas: coletânea. Brasília: ENAP, 2006. v.2, p. 219-238.

SANTOS, B. S.; AVRITZER, L. Introdução: para ampliar o cânone democrático. In: SANTOS, B S. (Org.). Para democratizar a democracia: os caminhos da democracia participativa. Rio de Janeiro: Civilização Brasileira, 2003.

SCHOMMER, P.; FRANÇA FILHO, G. Gestão Social e Aprendizagem em Comunidades de Prática: Interações conceituais e possíveis decorrências em processos de formação. In: SILVA JÚNIOR, J. T. et al. (Org.). Gestão Social práticas em debate, teorias em construção. 1. ed. Juazeiro do Norte: Editora Universidade Federal do Ceará, 2008, p. 8492.

SOUZA, C. Governos e sociedades locais em contextos de desigualdades e de descentralização. Ciência e Saúde Coletiva, v. 7, n. 3, p. 431-442, 2002.

Políticas públicas: uma revisão da literatura. Sociologias, Porto Alegre, ano 8, n. 16, jul./dez., p. 20-45, 2006. 
TENÓRIO, F. G. (Re)visitando o conceito de gestão social. In: SILVA JÚNIOR, J. T. et al. (Org.). Gestão Social práticas em debate, teorias em construção. 1. ed. Juazeiro do Norte: Editora Universidade Federal do Ceará, 2008, p. 5883.

TEODÓSIO, A. S. S. Parcerias tri-Setoriais na esfera pública: implicações, impasses e perspectivas acerca da provisão de políticas sociais em três experiências. Tese (Doutorado em Administração de Empresas) - FGV - Escola de Administração de Empresas de São Paulo, São Paulo, 2008.

VIANA, A. L. Abordagens metodológicas em políticas públicas. RAP, Revista de Administração Pública. v. 30, n. 2, p. 5-43, mar./abr. 1996.

WEIBLE, C M.; SABATIER, P. A.; MCQUEEN, K. Themes and Variations: Taking Stock of the Advocacy Coalition Framework. The Policy Studies Journal, v. 37, n. 1, 2009. 